\title{
Escola Mista e Igualdade entre os Sexos no Contexto Francês
}

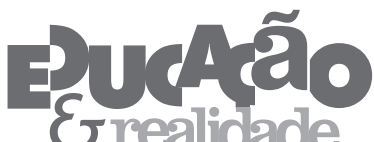 Erealidade}

\begin{abstract}
Nicole Mosconi ${ }^{\prime}$
'Université Paris Ouest Nanterre La Défense, Paris - França

RESUMO - Escola Mista e Igualdade entre os Sexos no Contexto Francês ${ }^{1}$. Este artigo analisa a introdução da escola mista no contexto educacional francês, problematizando os desafios presentes na efetivação de uma educação escolar igualitária. Para tanto, retomam-se, inicialmente, estudos clássicos desenvolvidos no campo da Sociologia da Educação e das Ciências da Educação francesas, e estabelece-se uma interlocução com a Sociologia da Educação inglesa. A noção de relação com o saber é apresentada como uma ponte para se discutir os efeitos que o processo de hierarquização dos saberes provoca na escolarização de meninas e meninos. O texto evidencia a necessidade de um trabalho contínuo que provoque mudanças nas desigualdades de gênero existentes na escola.

Palavras-chave: Gênero. Variável Sexo. Escolarização. Relação com o Saber.
\end{abstract}

ABSTRACT - Mixed School and Gender Equality in the French Context. This article analyzes the introduction of mixed school in the French educational context, problematizing the current challenges for an egalitarian school education. Therefore, it resumes, initially, classical studies developed on Sociology of Education and Science of Education fields in France, and establishes a dialogue with the British Sociology of Education. The notion of knowledge relation is presented as a bridge to discuss the hierarchic knowledge effects provoked on the schooling of girls and boys. The text highlights the necessity of a continued work in order to promote changes in the existing school inequalities.

Keywords: Gender. Variable Sex. Schooling. Knowledge Relation.

Educação \& Realidade, Porto Alegre, v. 39, n. 1, p. 221-239, jan./mar. 2014.

Disponível em: <http://www.ufrgs.br/edu_realidade> 
Escola Mista e Igualdade entre os Sexos no Contexto Francês

Este texto será desenvolvido em dois tempos. No primeiro, farei um histórico da introdução da variável sexo e do conceito de gênero nos trabalhos de Ciências Sociais e Humanas sobre a educação. No segundo, relatarei alguns resultados de pesquisa sobre a questão de gênero no sistema escolar, subdividindo-o em duas partes, condizentes às duas funções desse sistema: socialização e transmissão dos saberes.

\section{Histórico da Introdução da Questão de Gênero nas Pesquisas em Educação}

Neste item, mostrarei como as pesquisas introduzem progressivamente a variável sexo para pensar as diferenças e as desigualdades entre os sexos. Para tanto, retomarei a periodicização proposta por Catherine Marry, no livro Masculin-féminin: questions pour les sciences de l'homme (2001), que dialoga com discussões da Psicologia e as Ciências da Educação.

\section{Os Anos 1960-1970: variável sexo como variável secundária}

Nesse período, encontramos as grandes teorias da Sociologia da Educação, que mostram o fato de a laicidade republicana não efetivar, como se acreditava, a igualdade das chances sociais, mas, sim, a reprodução das desigualdades sociais. Entretanto, nada ou muito pouco é dito sobre a variável sexo.

Nesse contexto, um artigo pioneiro de Liliane Kandel, datado de 1975, apresenta-se como uma crítica feminista da Sociologia da época. No texto, intitulado L'école des femmes et les sciences de l'homme, a autora anuncia a releitura de algumas obras clássicas nas Ciências da Educação. Sua tese é a de que existe, em Educação, um duplo sexismo: o do sistema educativo e o do discurso das Ciências Sociais sobre este sistema.

Após discutir alguns fatos que mostram o funcionamento sexista do sistema escolar, como as diferenças de orientações, o acesso desigual ao ensino superior ${ }^{2}$ e à formação continuada ${ }^{3}$, as desigualdades educacionais nos países africanos e asiáticos ${ }^{4}$, Kandel (1975) apresenta as pesquisas da época produzidas pelo Institut National d'Études sur le Travail et l'Orientation Professionnelle (INETOP), entre os anos de $1963 \mathrm{e}$ 1964, tendo como orientação o final do Ensino Fundamental e os grandes livros de Pierre Bourdieu e Jean Claude Passeron, como Les heritiers: les etudiants et la culture, publicado em 1964, no qual Kandel sublinha a advertência: a variável sexo deve ser deixada de lado para se destacar o problema fundamental, como se a situação das mulheres não fosse um problema relevante. Depois, no livro Prime éducation et morale de classe, de Luc Boltanski (1968); em A reprodução ${ }^{5}$, de Bourdieu e Passeron (1970); e em L'école capitaliste en France, de Christian Baudelot e Roger Establet (1971), a autora constata que a censura e a ocultação da desi- 
gualdade dos sexos é geral. Não há exame sistemático, nem interpretação coerente dessas desigualdades de sexo no acesso aos diferentes níveis de ensino e nos destinos posteriores à escolarização. Do mesmo modo, não há tentativa de explicar esse fenômeno tendo como referência o estatuto e as funções concedidas às mulheres nas sociedades patriarcais. Diante disso, Kandel (1975) se pergunta se a análise dos processos educativos focada exclusivamente em termos de desigualdade de classes e de reprodução da sociedade capitalista não se constituiu em um obstáculo epistemológico maior em relação à apreensão e ao estudo de outros fenômenos de opressão e de exploração, em particular de um sexo pelo outro.

Liliane Kandel conclui seu artigo afirmando que a Sociologia da Educação deveria ser reescrita no feminino e propõe, como programa de pesquisa, o estudo dos fenômenos de transmissão ideológica; da aprendizagem dos papéis sexuados de dominação e de subordinação na escola e em outros espaços; das interações efetivas entre sexos nos grupos pouco formais e nas instituições escolares.

Mas, nesse momento, seu artigo é único em tal vertente. Entre os anos de 1960 e 1970, não se fala em termos de desigualdade de sexo - no máximo, de diferenças. E essas diferenças constatadas não são sustentadas por uma explicação teórica, visto que o saber do senso comum é tido como suficiente para explicá-las.

Além disso, trata-se do período da escola mista no sistema escolar francês, e não se tem, como na Grã-Bretanha, a necessidade de estudála de um ponto de vista sociológico (Dale, 1969; 1971; 1974). Disso decorre que não há controvérsias sobre quem se beneficia com a escola mista (Byrne, 1978; Deem, 1978; Spender, 1982). Vale ressaltar ainda que, na França, a pesquisa em educação não tem verdadeira legitimidade aos olhos da administração da Educação Nacional e das políticas, não recebendo muitos financiamentos.

Em entrevista publicada em 2010 na revista Travail, Genre et Sociétés, Kandel evoca os primeiras anos do feminismo da década de 1970 (Mosconi, 2010). Ela assinala que o movimento teve súbitos efeitos teóricos e nos diz:

Era preciso compreender por que essas verdades que nos cegavam, literalmente, pareciam ser invisíveis para todos. Por que elas não eram mencionadas, levadas em conta, estudadas pelos eruditos, pelos pensadores, pelas grandes construções teóricas que nos tinham inspirado e que nos ajudaram a pensar o mundo e nós mesmos (Mosconi, 2010, p. 16).

\section{Os Anos 1980: das diferenças às desigualdades}

As pesquisas começam a ser produzidas, mas as publicações são raras e continuam a falar genericamente sobre diferenças. Encontramos, por exemplo, no artigo de Jean-Claude Passeron e François De 
Escola Mista e Igualdade entre os Sexos no Contexto Francês

Singly (1984), Différences dans la Différence: socialisation de classe et socialisation sexuelle, a constatação de que há diferenças importantes nas representações das meninas e dos meninos pertencentes às mesmas classes sociais. A maneira como a pesquisa francesa em educação começa a se interessar pela variável sexo é ainda estreitamente focada.

Em 1981, a esquerda chega ao poder e se preocupa com a baixa porcentagem de meninas nas áreas científicas e de técnicas-industriais. Espera, então, suprir com as medidas adotadas a falta de mão de obra nesse campo e o desemprego das mulheres, incentivando sua inserção nessas áreas. A pesquisa deveria compreender nesse momento por que um número pequeno de mulheres optava por essas áreas, e encontrar os meios de incitá-las a essas escolhas.

Porém há um outro fator essencial que permite entender o interesse pela variável sexo na pesquisas. Trata-se do movimento feminista, que ocasiona uma entrada maciça de mulheres e de feministas na universidade, o que conduz, consequentemente, a um envolvimento progressivo de mulheres com a atividade de pesquisa. Essas pesquisadoras vão investigar, então, temas que tinham sido negligenciados pelos homens até aquele momento, como as questões relativas à educação das meninas e das mulheres, dentre outros assuntos.

Na mesma direção dos trabalhos de Kandel, as pesquisadoras em Ciências Sociais e Humanas erguem uma obra crítica na qual mostram que os sociólogos, ao considerarem a variável sexo, faziam-no de um modo que traía seus próprios princípios explicativos, argumentando de modo naturalista e simplista diferenças existentes entre meninas e meninos. Termos como aptidões, motivações, vocações ou mentalidades diferenciadas eram empregados pelos sociólogos, que recorriam, ainda, a uma psicologia selvagem ou a uma sociologia espontânea como fonte explicativa.

Essas estudiosas evidenciaram o fato de que as mentalidades não poderiam ser analisadas independentemente das práticas efetivas, e que, de outro lado, o que era chamado de diferenças entre os sexos cobria, na realidade, desigualdades de sexo. Elas sustentaram, sobretudo, que, para explicar essas desigualdades de sexo, uma teoria era tão necessária quanto para se explicar as desigualdades de classes.

Nesse momento, é perceptível que há uma evolução, por exemplo, na orientação do trabalho realizado no INETOP com a chegada de psicólogas feministas, como Cendrine Marro e Françoise Vouillot. Elas argumentam que a concepção do Instituto é guiada por normas muito estereotipadas de masculino e de feminino, e que isso não decorre de uma questão de competências cognitivas, mas, sim, de identidade sexual.

Por outro lado, na Sociologia, algumas pesquisadoras tentam transpor as grandes teorias sociológicas para explicar as desigualdades de sexo no sistema escolar francês: a teoria do individualismo metodo- 
lógico à maneira de Raimond Boudon (Duru-Bellat, 1990), ou as teorias da dominação.

É essa última perspectiva que adotei em minha investigação realizada entre os anos de 1980-1985. Como meu objetivo era trabalhar em uma abordagem clínica psicanalítica, situei-me na corrente da sociopsicanálise de Gérard Mendel que, a meu ver, tinha a vantagem de associar uma teorização sobre as instituições, inspirada no marxismo, a uma referência psicanalítica. Nessa pesquisa, discutia que a escola mista havia sido introduzida sem debate público, que não havia sido pensada, refletida e que ela não era objeto de uma política e de uma pedagogia articuladas. Problematizei, ainda, que seu objetivo não era, de modo algum, a igualdade dos sexos, mas a questão orçamentária.

Nesse trabalho, concluí que havia uma formação de compromisso subjacente ao modelo formal de acesso igualitário de todos e todas aos saberes que a escola mista representava. Para além da perspectiva supostamente igualitária, subsistia uma relação de desigualdade entre os sexos. Encontrávamos muito frequentemente, nos discursos dos professores e das professoras, bem como dos alunos e das alunas, esquemas tradicionais sexistas, por isso denominamos, na época, tratar-se de um falso-semblante de igualdade.

Encontramos na mesma época a tese realizada por Marlaine Cacouault-Bitaud (2007) na área de Sociologia, sobre os professores do ensino médio. Partindo da Sociologia das profissões e das teorias feministas sobre o trabalho das mulheres, a pesquisadora analisa as desigualdades entre mulheres e homens no exercício do magistério, em função da interdependência entre vida pessoal e vida profissional, o que determina configurações bem diferenciadas da atividade profissional e da carreira.

As primeiras pesquisas em Ciências da Educação foram feitas nos anos 1980, mas é, sobretudo, a partir dos anos 1990 que encontramos uma ampliação das publicações sobre esse tema.

\section{Os Anos 1990: a abertura da caixa preta da escola}

Nesse contexto, situamos a publicação dos livros A Escola das Meninas, de Marie Duru-Bellat (1990) e, em seguida, Allez les filles, de Baudelot e Establet (1992). Esses autores recusam uma ideia recorrente nos anos 1970, encontrada na escola de Bourdieu, de que as interações entre sexo e classe resultam de um acúmulo de deficiências (ou de privilégios) ${ }^{6}$. Ao contrário, Baudelot e Establet (1992) mostram em seu trabalho que nas classes populares o sexo neutraliza em parte a deficiência das meninas, pois elas têm êxito, assim como os meninos de classes intermediárias. Todavia observam que há, ainda, uma grande porcentagem de meninas de classes populares em situação de fracasso escolar e que, para esse grupo, há pouca possibilidade de inserção na escola profissionalizante em função da significativa segregação aí presente.

Educação \& Realidade, Porto Alegre, v. 39, n. 1, p. 221-239, jan./mar. 2014. 
Escola Mista e Igualdade entre os Sexos no Contexto Francês

Baudelot e Establet (1992) têm, entretanto, tendências a reproduzir as explicações habituais do sucesso escolar das meninas como sendo decorrentes de sua docilidade e submissão às normas escolares, atributos vistos quase como defeitos, já que essas qualidades tornam-se características limitadoras para as meninas nas áreas profissionais mais concorridas. No que se refere aos meninos, os autores assinalam que a indisciplina é considerada um defeito apenas para aqueles oriundos das classes populares, já que, para os das outras classes, isso seria uma prova de independência e de autonomia. Ressaltam, ainda, não haver nenhuma preocupação no sentido de sensibilizar as meninas quanto a esses modos de ser.

Baudelot e Establet (1992) afirmam que a escola está adiantada em relação à família nessa construção, porém eles insistem pouco sobre o fato de que a escola tem também sua participação na socialização desigual das meninas e dos meninos. Como assinala Duru-Bellat (1990; 1995), meninos e meninas vivem na instituição escolar e no cotidiano das salas de aula uma socialização bem diferenciada segundo o sexo, e não apenas diferente, mas também desigual. Para evidenciar esse fato, não se deve contentar com as estatísticas, é preciso realmente penetrar na caixa preta da escola, na vida cotidiana dos estabelecimentos de ensino e no seu funcionamento concreto.

Essa perspectiva é adotada, por um lado, em pesquisas realizadas na área da Sociologia, como no trabalho de Georges Félouzis (1994) sobre o colégio, Le collège au quotidien; na investigação de Gilles Moreau (1994) sobre o liceu profissional, Filles et garçons au lycée professionnel; e na pesquisa de Claude Zaidman (1996) sobre a escola primária, La mixité à l'école primaire; e, por outro lado, nos trabalhos desenvolvidos nas Ciências da Educação, em pesquisas sobre o ensino da matemática no primário, de Annette Jarlégan (1999), na tese de Leila Acherar (2003) sobre a escola maternal e na investigação por mim realizada (1989).

Outro aspecto que pôde ser detectado de maneira mais precisa ao se abrir a caixa preta da escola se refere à questão de gênero na socialização escolar.

\section{O Gênero na Socialização Escolar: a transmissão dos estereótipos de sexo}

Nesta seção, discutirei os modos de transmissão dos estereótipos de sexo na dinâmica escolar, abordando tanto a relação entre professores/as e alunos/as quanto o que se passa entre os próprios estudantes.

\section{Gênero e Estereótipos de Sexo}

Opero com o conceito de gênero, entendendo-o como um 
[...] sistema social que institui uma ordem social na qual tanto um sexo quanto outro estão em uma relação de dominação que se traduz, em termo simbólico, por um sistema de norma de sexo (o masculino, o feminino), interdependentes e hierarquizantes, concernentes tanto aos atributos físicos e psicológicos, quanto aos papéis e condutas, inclusive de relação entre os sexos (Marro, 2011).

Cabe aqui uma observação: não é porque se discutem as desigualdades de sexo que se devem negligenciar as desigualdades sociais de classe ou de culturas. Essas desigualdades podem se combinar, compensar ou se acumular, fazendo com que alguns sujeitos sejam alvo de vários tipos de discriminação. Como ilustração disso, observamos que meninas de classes populares têm, em média, mais êxito escolar do que os meninos - questão discutida atualmente a partir do conceito de intersecionalidade. Esse conceito permite abordar as posições ocupadas por pessoas que convivem com relações de poder distintas (de classe, de raça e de sexo), quer dizer, que são objeto, de uma só vez, do racismo, sexismo e classismo (Dorlin, 2008).

Do conceito de gênero, deriva-se o conceito de estereótipo de sexo - uma noção oriunda da Psicologia Social que se mostra pertinente para auxiliar no deciframento do que acontece nas relações cotidianas, em particular na escola. Os estereótipos de sexo são entendidos, aqui, como crenças que atribuem características diferentes às mulheres e aos homens com a finalidade de hierarquizá-los: o masculino é valorizado e o feminino é desvalorizado, conforme a ordem sexual, como assinala Réjane Sayac-Slawinski (2007).

A Psicologia Social tem mostrado, ainda, que os estereótipos orientam e alteram o olhar sobre outrem, os julgamentos, as expectativas, as condutas, e que esses efeitos se produzem sem que o sujeito esteja consciente disso. Na Psicologia Social, esse processo é denominado cognição social implícita (Hurtig; Pichevin, 1986). Tais efeitos podem se produzir em qualquer pessoa, pois, como afirmava a psicóloga MarieFrance Pichevin (1995), nós somos todos sexistas, e, em particular, na escola.

\section{As Relações entre Pares na Escola}

A Psicologia Social nos ensina que a mistura ${ }^{7}$ de um grupo amplia aquilo que é mais proeminente da categoria de sexo. As categorias de sexo sobressaem e exercem uma pressão em direção a uma conformidade sexual nos indivíduos.

Nas relações entre os alunos nos pátios de recreação, os meninos ocupam o espaço com os jogos mais dinâmicos, empurrando as meninas para as bordas do pátio. Eles encenam a oposição: homens fora, mulheres dentro, como destaca Zaidman (1996). Na sala de aula, observa-se que os meninos ocupam o espaço sonoro da aula (Zaidman, 1996).

Educação \& Realidade, Porto Alegre, v. 39, n. 1, p. 221-239, jan./mar. 2014. 
Escola Mista e Igualdade entre os Sexos no Contexto Francês

Eles interveem muito mais do que as meninas, sem terem sido convidados por professores e professoras. Tentam ser percebidos, seja por seus saberes, seja por sua indisciplina.

Além disso, na adolescência, alguns meninos exercem um domínio no grupo-sala, impedindo as meninas de tomar a palavra e, sobretudo, de ocupar uma posição de liderança na classe. Eles o fazem valendo-se de diversos meios: a ridicularização, a zombaria, as gozações sexistas. Esses fenômenos se exacerbam na Educação Profissional e Tecnológica ${ }^{8}$.

\section{As Relações Professores-alunos}

Os estereótipos de sexo estão presentes, também, na mentalidade dos docentes e dos adultos, em geral, que atuam na escola. Eles dirigem seus olhares para os alunos, seus julgamentos, suas expectativas, suas condutas, sem que se deem conta disso (cognição social implícita).

Numerosas pesquisas mostram que os professores e as professoras mantêm mais interação com os meninos do que com as meninas, mas, para que essas diferenças de tratamento possam ser explicadas, devem-se cruzar dados como sexo, posição escolar e origem social dos alunos.

As pesquisas de Jarlégan (1999) sobre a interação em classe, realizadas em Nancy, indicaram que os professores e as professoras interrogam mais frequentemente os meninos, em especial aqueles que ocupam uma posição de destaque, fazendo-lhes mais observações de natureza cognitiva, dirigindo-lhes questões mais complexas, retomando mais regularmente suas intervenções e dando-lhes mais tempo para responder (tempo de latência).

Os estereótipos governam, ainda, as expectativas e os julgamentos dos professores. Eles esperam a docilidade das meninas e a indisciplina dos meninos, daí decorrendo uma dupla padronização:

- Sobre os comportamentos em sala: professores e professoras aceitam a dominação dos meninos, mas não a das meninas. A indisciplina dos meninos é julgada insuportável, porém inevitável, ao passo que a indisciplina das meninas é rejeitada e vista como um ataque pessoal.

- Dupla padronização, também, no trabalho escolar: professores e professoras pensam que os meninos podem fazer melhor, como se eles apresentassem capacidades ocultas que não aparecem, entretanto, em suas performances efetivas pelo fato de eles não estudarem o suficiente. Já as meninas são vistas como aquelas que fazem o que podem. Seus resultados são atribuídos mais ao seu trabalho do que às suas capacidades, e em relação a elas não se supõe a existência de potencialidades ocultas. 
Quando pensamos no tempo que os alunos passam em sala durante toda a sua escolaridade, temos dificuldade em refletir que essas experiências cotidianas não tenham efeitos. Sabe-se que na adolescência as meninas acreditam que se elas não têm sucesso escolar é porque não têm dom, em particular na área de matemática. Já os meninos pensam que é porque eles não estudam o suficiente, ou porque o professor não explicou bem a matéria. Por outro lado, pesquisas mostram que, na adolescência, as meninas têm um sentimento de competência e autoconfiança menor do que os meninos, mesmo quando os resultados escolares são idênticos. Pode-se pensar que esses julgamentos de professores e professoras produzem efeitos Pigmaleão (efeito de profecia autorrealizadora): se professores e professoras atribuem capacidades menores às meninas, elas acabam persuadidas de que, de fato, possuem menores condições do que os meninos.

\section{Algumas Ilustrações}

Apresentarei neste item dados de pesquisas que foram realizadas no grupo coordenado por Claudine Blanchard-Laville (Blanchard-Laville et al., 1997; Mosconi; Beillerot; Blanchard-Laville, 2000). Trata-se de um trabalho de observação e análise de gravações em áudio e vídeo de aulas de matemática, realizado por uma equipe composta de nove pesquisadores, sendo oito com formação em matemática. O grupo partilha referências teóricas distintas, em temáticas como didática, psicossociologia, sociologia e psicanálise. Todo o grupo realiza observação clínica e socioclínica (Blanchard-Laville, 1999), em uma perspectiva de codisciplinaridade (Blanchard-Laville, 2000). Seu desafio não é o de observar um grande número de salas de aula, mas, sim, de analisar mecanismos extremamente finos e pouco visíveis que, supõe-se, desempenham um papel importante no cotidiano da classe, nas aprendizagens dos alunos, na sua socialização em termos de sexo, e mesmo na constituição daquilo que é denominado pela equipe como relação com o saber ${ }^{9}$.

Nas pesquisas que passarei a discutir, pretendo avaliar resultados clássicos sobre a falta de proporção entre as interações e, também, introduzir análises mais qualitativas.

O primeiro exemplo refere-se à gravação de uma aula de matemática, realizada no quarto ano do Ensino Fundamental (CM1), em uma turma composta por 15 meninos e 11 meninas, sobre a escrita dos grandes números. A aula tem uma duração de uma hora e é ministrada por uma professora, em uma escola experimental de Bordeaux (BlanchardLaville et al., 1997). Trata-se de uma aula bem animada e interativa, havendo uma desigualdade das interações em favor dos meninos ${ }^{10}$, sobretudo se considerarmos o tempo consagrado a uns e outros ${ }^{11}$.

Devemos notar que essas diferenças dissimulam, ainda, grandes desigualdades em cada grupo dividido por sexo, segundo sua origem social e sua posição escolar ${ }^{12}$. Mas, considerando esses fatores, percebe- 
Escola Mista e Igualdade entre os Sexos no Contexto Francês

mos que com a origem social e a posição escolar iguais, as diferenças de sexo continuam visivelmente presentes.

De um ponto de vista qualitativo, as ordens complexas (explique, reflita, está claro para você agora) são reservadas para alguns meninos, ao passo que as meninas e os outros meninos recebem diretivas mais simples (faça isto, escreva isto, diga). O não verbal, o gestual é importante também: quando a professora pega um menino pelos ombros é para aproximar-se fisicamente dele e convidá-lo a refletir; quando ela toca uma menina, é para distanciar-se dela e dirigi-la para seu lugar na sala. Isso é apenas a demonstração de um momento pequeno, mas significativo.

A segunda classe é uma sala de aula que reúne dois níveis diferentes de escolarização - Pré-Escola (CP) e primeiro ano do Ensino Fundamental (CE1) -, ministrada por um professor em início de carreira. Dessa turma, dispomos de registros de três jornadas e meia de trabalho escolar, sendo uma por trimestre, e de entrevistas realizadas com o professor depois das gravações.

Nesse material, também encontramos evidências das desigualdades presentes no tratamento dirigido aos meninos e às meninas. Porém, por meio dele, fizemos uma outra descoberta referente ao lugar ocupado pelos alunos ao longo do ano escolar: os meninos se encontram cada vez mais próximos da mesa do professor e, por conseguinte, as meninas cada vez mais distantes.

A explicação atribuída pelo professor a esse dado é que ele quer ajudar os alunos que se encontram em dificuldades, e que não são suficientemente autônomos para trabalhar sozinhos nas atividades escolares. Todavia essa justificativa se aplica apenas aos meninos, visto que as meninas em situação de dificuldade não estão fisicamente próximas do professor. Ao contrário, ao lado dele se encontra uma aluna que apresenta um nível elevado de aprendizagem, a quem ele delega uma função de auxiliá-lo pedagogicamente junto a duas meninas que apresentam dificuldades.

A partir dos registros dessa sala, podemos ilustrar, também, a clássica noção de dupla padronização, por meio da presença de critérios diferenciados de apreciação dos comportamentos dos meninos e das meninas. O professor nos apresenta um plano de trabalho da turma com o nome dos alunos, no qual se encontra escrito, na parte inferior da folha: "Imad e Brahim, muito vivos; Sarah, perturbadora".

Por fim, passarei a discutir a influência que os professores podem desempenhar no processo de aprendizagem dos alunos e na sua relação com o saber. Para tanto, retomarei uma situação ocorrida em uma turma de sétimo ano do Ensino Fundamental (5ème), de um colégio localizado em uma Zona de Desenvolvimento Prioritário (ZDP), composta de 15 meninas e nove meninos. 
Após o registro das atividades realizadas em sala, foi feita uma entrevista com o professor sobre cada aluno e aluna. A observação minuciosa realizada nessa sala permitiu analisar a maneira como o professor atribuía uma posição diferenciada às meninas e aos meninos em relação ao saber matemático.

Trata-se de uma aula sobre multiplicação de frações. O professor tem um estilo de ensino bem diretivo, de modo que tudo é calculado: os alunos devem terminar a frase que o professor inicia-como uma missa, assinalou uma das pesquisadoras. A aula se desenvolve a partir de uma sucessão de exercícios que os alunos tentam fazer, primeiramente sozinhos em suas carteiras, sendo cada aluno ou aluna chamado, posteriormente, no quadro para fazer as correções.

Na equipe, fazemos uma análise didática do que é registrado. É importante ressaltar que, no caso dessa aula, o número de interações é maior com as meninas ${ }^{13}$, mas com um detalhe: todas as meninas que realizam as atividades no quadro, inclusive a aluna considerada a melhor, apenas escrevem o que é ditado pelo professor, como se fossem pequenas secretárias. A passagem das meninas por essa atividade é bem curta, durando, em geral, menos de um minuto, sendo difícil considerar que essa tarefa lhes possibilite construir um saber matemático.

Depois da institucionalização da regra de multiplicação das frações, é o momento de aprender a simplificar, de modo a obter uma fração irredutível. Nesse momento, ocorre o mesmo fenômeno observado na classe de quarto ano do Ensino Fundamental, citada anteriormente: o professor interroga o melhor aluno da sala. Trata-se de um aluno, segundo relato do professor em entrevista, considerado "o melhor da sala, inteligente, descontraído, excelente!”. Vemos assim que, para construir um saber novo, o professor se dirige aos meninos, enquanto que para recordar um saber já trabalhado é às meninas que o professor se dirige, como se jogasse com os polos tradição e criação.

Entretanto esse aluno se perde no exercício de simplificação, e o professor pede auxílio a uma menina: "Você pode ajudá-lo? Ele teve um branco! É estranho isso acontecer com ele, mas isso acontece...”. Dizendo de outra maneira, mesmo os melhores podem se enganar e não se perde a confiança em suas capacidades por causa disso, cabendo a uma menina ajudá-lo - o cuidado, às meninas. Em seguida, é o professor mesmo que auxilia o aluno, levando-o ao resultado passo a passo, como ele faria se se tratasse de um aluno considerado mediano. E é aí que se encontra um ponto interessante para a investigação: a proxêmica. $\mathrm{O}$ professor se coloca bem próximo ao aluno e lhe fala na primeira pessoa: "Eu preciso de um produto de fatores!", "Mas eu vi que havia uma ligação entre 7 e 21!”, como se ele se colocasse dentro da cabeça do aluno.

Após a finalização desse exercício, será a vez do professor interrogar uma aluna. Sobre essa estudante, ele havia dito o seguinte em entrevista: "Ela causou boas impressões no início, teve uma boa participação no primeiro trimestre e depois ela teve outras preocupações, e então 
Escola Mista e Igualdade entre os Sexos no Contexto Francês

tudo piorou.... Acrescentando em seguida: "É uma aluna caprichosa, uma desmemoriada... Diante de qualquer coisa, ela chora, vem com sua histeria”. Essa aluna tinha passado de uma média de 12 para uma média de oito.

A aluna permanece sete minutos no quadro, fato geralmente reservado aos bons alunos. Mas, no seu caso, a pergunta colocada pelo professor parece ser mais um acerto de contas. A aluna age com lentidão e inércia, e o professor a importuna: “Ande, mais rápido!” (17 vezes), até que, ao final, ele a manda de volta para seu lugar, dizendo: "Vamos, que vergonha!".

É importante ressaltar que, durante o tempo no qual a aluna se encontrava no quadro, o professor se manteve no fundo da sala, sentado em uma mesa bem longe dela. Ora, a distância entre um professor e um aluno guarda um sentido bastante simbólico: encontramo-nos mais próximos de um aluno quando esperamos mais dele.

O menino, aos olhos do professor, sintetiza, ao mesmo tempo, a excelência em matemática e a docilidade, e auxiliá-lo didaticamente é duplamente gratificante. Quando o professor o convida para realizar a atividade no quadro, diz: "Venha nos mostrar como você fez". Nesse caso, há uma possibilidade de construir uma relação positiva em direção à matemática. Já a menina simboliza a indocilidade - "ela quer ser notada".

Durante seu interrogatório, ao professor que lhe diz "Faça o que deve ser feito", a aluna responde "Eu não estou entendendo, professor", mas o professor não tenta lhe explicar, pois ele toma essa demanda da parte da aluna apenas como uma marca de não submissão, pois ela é uma rebelde que deve ser domada, e até mesmo humilhada. Mas o que a aluna pode concluir dessa situação é que aprender matemática não é uma reivindicação legítima quando parte de uma menina. Se essa experiência se repetir, o que poderia ocorrer, já que o professor relatou que a aluna chora, como ela poderia construir uma relação positiva com a matemática? E mesmo suas colegas de classe, a quem não se demanda nada além de escrever operações ditadas, também não teriam melhores possibilidades de construir uma relação positiva.

Para concluir o ponto referente às interações didáticas, podemos dizer que na escola se operam aprendizagens sociais, são transmitidos modelos, representações, comportamentos, papéis, valores, normas de sexo que ensinam aos alunos modos de construir suas identidades sexuais, aquilo que os ingleses chamam de currículo oculto (Young, 1971; Forquin, 1985), conteúdos que não fazem parte do programa e dos objetivos do sistema escolar, mas que são aprendidos a despeito da vontade de todos.

Na escola, adquire-se uma certa imagem de si mesmo, conforme a ordem social dos sexos, que implica posições sociais e sexuais desiguais. Entretanto essa aprendizagem, como já foi visto, não se faz so- 
mente por meio da socialização, mas também através das aprendizagens disciplinares.

Passarei, então, a ampliar essa discussão, abordando a natureza dos conteúdos ensinados na escola.

\section{Gênero e Saberes: o currículo oculto e a discussão social e sexual dos saberes}

Neste item, discutirei três pontos: os saberes que ensinamos, os saberes que não se ensinam e, por fim, a bicategorização sexual das disciplinas.

\section{O Currículo Oculto nos Conteúdos de Ensino}

Sabe-se que, dentre os inumeráveis saberes que existem hoje nas sociedades, as autoridades de um sistema educativo devem escolher aqueles que são considerados dignos de ser transmitidos e aprendidos na escola: é a questão das escolhas curriculares, tema discutido pela sociologia inglesa, quando distingue currículo formal, real e latente. Desse ponto de vista, há os saberes que são ensinados e os que não o são. Os saberes ensinados contribuem para conformar um mito comum em nossas sociedades, e até mesmo entre os eruditos: trata-se do mito de que existem grandes homens, gênios na política, nas ciências, assim como nas artes, mas não existem grandes mulheres. A expressão chega até mesmo a nos parecer estranha. Porém, ainda que o gênio e o feminino se excluam, poderíamos imaginar que o currículo incluísse mulheres importantes na história, que produziram ações, saberes e obras em todas as áreas.

Estando as mulheres quase ausentes dos programas escolares, a crença que se insinua, quando ela não é explícita, é a de que elas não existem, que as mulheres nunca fizeram nada de importante na história, na política, nas ciências, na cultura, na literatura, nas artes. Ora, como ressalta Michele Le Doeuff (1998), o existente é uma base para desenhar o possível, para demonstrar uma atividade como sendo aberta. Nesse sentido, pode-se rapidamente depreender desse fato a ideia de que as mulheres podem adquirir saberes, mas que elas são incapazes de inovações nesse campo ou de ter uma ação ou um pensamento considerado original. Essa crença é perniciosa para as meninas, pois não as ajuda a se valorizarem como futuras mulheres, podendo afetar a sua crença em si mesmas, caso elas tenham o desejo de levar à política, à cultura ou ao saber comum, seu toque pessoal. E essa certeza é ainda mais nefasta para os meninos, que permanecem confortáveis na ideia da superioridade intelectual masculina.

Essa hierarquia entre os sexos, presente nos saberes transmitidos na escola, é um elemento essencial da contribuição dos saberes escolares para a reprodução do gênero, mas há algo ainda mais pernicioso. 
Escola Mista e Igualdade entre os Sexos no Contexto Francês

\section{Os Saberes que a Escola Não Ensina}

Dentre os saberes que a escola não ensina, há os saberes críticos que mulheres ou homens produziram na história para evidenciar as desigualdades de sexo. Esses saberes são particularmente importantes para ressaltar as múltiplas formas de privação de liberdade, de ciência e de poder que as mulheres sofreram e ainda sofrem. $\mathrm{O}$ acesso a esse saber é essencial para resistir à dominação exercida por outrem. Por falta de uma transmissão desses saberes críticos, o sistema escolar não ajuda os/as jovens a pensar por si mesmos/as no domínio das relações de sexo. Contribui, ainda, para a consagração das divisões sociais e sexuais, e para o fortalecimento da crença de sua imutabilidade, reconfortando, assim, a ordem sexual.

Poder-se-ia dizer, com Le Doeuff (1998), que a escola produz "bloqueios cognitivos na percepção das relações sociais que as implicam" (p. 17), tanto para os meninos quanto para as meninas. A escola transmite uma cultura que não permite às mulheres e às meninas considerar com lucidez as desigualdades de sexo, tomar consciência das formas de dominação que os homens lhes impõem e que as deixam desamparadas em relação às suas condições de vida. Ao mesmo tempo, ela produz meninos e homens que se encontram bem instalados em seu direito legítimo de dominadores, e que, em vez de perceberem nas vontades de emancipação das meninas e das mulheres uma oportunidade de se tornarem, eles também, mais humanos, conservam o poder e o prestígio "[...] que seu estatuto social de macho lhes proporcionou desde a infância” (Le Doeuff, 1998, p. 104).

Pode-se dizer então que, nessa organização dos programas escolares, o gênero como construção social da hierarquia dos sexos funciona plenamente. Ele reparte de forma desigual as "condições psíquicas e imaginárias do exercício do pensamento” (Le Doeuff, 1998, p. 226), dos saberes e das práticas. De outro modo, os programas tecem em torno dos seus alunos, como sujeitos cognitivos, toda “[...] uma rede imaginária de representações de si, autorizações e interdições, fontes de inibições que são mais fortes do que as condições apenas intelectuais do pensamento" (Le Doeuff, 1998, p. 226). Os homens e meninos são muito mais levados a fomentar fantasmas de onipotência, enquanto as mulheres e as meninas são muito mais incitadas aos fantasmas de impotência, ou aos sentimentos de indignação que representam, nas duas fórmulas, fatores de inibição do pensamento. É muito melhor construir um “[...] imaginário positivo, mas mensurado por si” (Le Doeuff, 1998, p. 226).

Outro aspecto são os mitos e o imaginário que rodeiam as disciplinas escolares.

\section{A Bicategorização Sexual das Disciplinas}

As disciplinas são sexuadas da mesma forma que as trajetórias escolares. Mesmo que os saberes não sejam sexuados em seus conteúdos, 
nossas crenças concernentes às disciplinas escolares tendem a dividilas por sexo.

Essas crenças são variáveis. No século XIX, não eram as ciências, mas as letras (as humanidades clássicas) que eram valorizadas e feitas para os meninos da burguesia. E as meninas da burguesia não tinham acesso a esses conhecimentos pelos programas dos liceus de meninas, criados pela Lei Camille Sée, em 1880. A passagem das letras para as ciências se fez na segunda metade do século XX.

É sabido que essas crenças são arbitrárias, mas esse imaginário coletivo é bem poderoso. Acredita-se que existem disciplinas masculinas e disciplinas femininas. Essa visão não está presente apenas nos alunos, ela existe também nos adultos, mesmo que eles se esquivem frequentemente dessa afirmação. Por exemplo, existe uma grande expectativa de que os meninos terão maior êxito nas disciplinas científicas, e que as meninas o terão nas matérias literárias.

Na escola, então, os alunos não vão aprender apenas os conteúdos disciplinares, mas, também, que a matemática e a física são áreas masculinas, dirigidas aos meninos. Como diziam os sociólogos Baudelot e Establet (1992, p. 126): "Você tem que gostar de matemática, meu filho, mesmo que você não compreenda nada”, pois os pais também aprenderam essas divisões quando frequentaram a escola. Diante disso, algumas meninas pensarão que a matemática não é para elas, e que o estudo da língua francesa, das línguas em geral, da biologia é feminino, isso sim é para as meninas, e os meninos são levados a pensar isso não é para mim.

As pesquisas mostram que, desde o Ensino Fundamental, as meninas declaram preferir as letras e as línguas, e os meninos a matemática e a informática (Félouzis, 1994). Essas preferências se exprimem, ainda mais nitidamente, nos níveis seguintes de escolarização.

Desse modo, não causa surpresa constatar que, no momento da escolha profissional, depois do ensino obrigatório, meninos e meninas se dirijam para inserções no mundo do trabalho diferenciadas e hierarquizadas, em função do mercado e do prestígio relativo aos ofícios e às profissões. Provavelmente, essas orientações também ocorrem em função da segmentação do mercado de trabalho, pois os ofícios também são divididos e hierarquizados segundo estereótipos: ofícios de homem, ofícios de mulher. E essa divisão reflete bem as grandes distinções existentes nos percursos escolares (produção e serviços para o ensino profissional; terciário e indústria para o ensino tecnológico; ciências e letras para as trajetórias profissionais em geral).

Vemos, então, que a organização do sistema escolar é bem traçada para que os jovens se adaptem sem muita resistência a esse mercado de trabalho segmentado e hierarquizado. E diante dessa relação entre as divisões do mercado de trabalho e das trajetórias escolares, sugiro retomar o conceito de "divisão social e sexual do trabalho", proposto por Margaret Maruani e Chantal Nicole-Drancourt (1989), para falar em

Educação \& Realidade, Porto Alegre, v. 39, n. 1, p. 221-239, jan./mar. 2014.

235

Disponível em: <http://www.ufrgs.br/edu_realidade> 
Escola Mista e Igualdade entre os Sexos no Contexto Francês

"divisão social e sexual dos saberes", pois o sistema escolar opera por meio de seleção.

Não se pode compreender essas orientações diferenciadas e suas consequências profissionais e sociais sem considerar a socialização diferenciada e desigual que ocorre na família. Cabe notar que na adolescência os meninos pensam apenas em seu futuro profissional, enquanto as meninas se preocupam, também, com o tempo que lhes será necessário para se dedicar à família. Para os meninos, isso não é de modo algum uma questão.

É esse conjunto de fatores que contribui para a reprodução das desigualdades entre os sexos e que constitui o gênero como ordem social de desigualdade entre os sexos, tanto na escola como na sociedade de uma forma geral.

\section{Considerações Finais}

Ao longo do artigo, tivemos a oportunidade de verificar como as pesquisas que associam gênero e educação demoraram a ser efetivadas no contexto francês. Nós ainda não realizamos o programa de investigação proposto por Kandel (1975). Além disso, as pesquisas desenvolvidas não foram bem divulgadas entre formadores/as de professores e professoras, entre os docentes, no campo das Ciências da Educação, dentre outros.

Durante esses anos de pesquisa sobre o sistema educacional, temse insistido no fato de que os processos seletivos tendem a reproduzir as divisões entre as classes, mas trabalha-se pouco os modos como essa divisão pode se combinar com uma segmentação entre os sexos e mesmo entre grupos étnicos.

A educação mista foi introduzida tardiamente na escola francesa (1960-1970) e é importante sublinhar que tal processo ocorreu sem clareza das suas finalidades e objetivos.

Para implementar as recomendações europeias, o poder político produziu textos que preconizavam medidas em favor da igualdade dos sexos na escola - como a Convenção de 2000, que foi renovada em 2006 -, mas os meios para sua efetivação não foram aprofundados. Esses documentos não são muito conhecidos, e seus objetivos estão longe de serem considerados prioridades.

Preconiza-se que a escola mista seja suficiente para promover a igualdade entre os sexos, mas tal processo demandaria uma verdadeira educação em direção à igualdade. Poucos integrantes do quadro da Educação Nacional parecem convencidos desse ponto, e um número menor ainda se dispõe a tomar decisões nesse sentido. Apenas uma pequena parte de sujeitos que atuam nesses espaços demonstram criatividade e disponibilidade quanto a essa questão. Paradoxalmente, esses sujeitos são considerados militantes, embora o que eles façam seja apenas aplicar o que é recomendado pelos textos oficiais. Os quadros

236 Educação \& Realidade, Porto Alegre, v. 39, n. 1, p. 221-239, jan./mar. 2014 Disponível em: <http://www.ufrgs.br/edu_realidade> 
intermediários do sistema educativo, por sua vez, não seguem essas orientações, embora sejam os únicos a terem os meios de tornar essas medidas obrigatórias e efetivas, de modo que todos se sintam responsáveis por sua aplicação. Há o fato, ainda, de que a sociedade se encontra, ela mesma, em conflito e que isso também repercute no sistema escolar, paralisando-o.

Finalizando, deve-se sublinhar que a escola mista é indispensável como afirmação do princípio republicano referente à igualdade do direito de acesso de todos a todos os saberes. Verifica-se, assim, um progresso em relação à situação anterior de segregação dos sexos que produzia, sem dúvida, mais desigualdades diante dos saberes. Mas, nesse regime de escola mista atual, encontra-se uma igualdade formal sem uma real igualdade diante dos saberes. Nesse sentido, constata-se, apenas, a igualdade de oportunidades, o que quer dizer uma igualdade de direitos formal entre as classes e entre os sexos, que não permite, contudo, a passagem da igualdade dos direitos à construção de um verdadeiro direito à igualdade na educação - direito universal aplicado tanto às meninas quanto aos meninos.

Recebido em 11 de junho de 2012 Aprovado em 19 de agosto de 2012

\section{Notas}

1 Título original do artigo: Historique des recherches sur la mixité et l'égalité des sexes en éducation en France.

2 Na maior parte dos países europeus, os meninos tinham, na época, de um e meio a duas vezes mais chances de continuar seus estudos do que as meninas após o bac (N. de T.: Após o término do Ensino Médio, no caso brasileiro. Procurou-se, ao longo da tradução deste artigo, adaptar as referências de seriação dos sistemas de ensino citados à realidade educacional brasileira, na medida do possível).

3 A Association pour la Formation Professionnelle des Adultes (AFPA) acolheu, em 1971, apenas $7 \%$ de mulheres.

4 Há duas vezes mais meninos do que meninas nas escolas.

5 No caso dos livros traduzidos para o português, optamos por colocar os títulos nessa versão (N. de T).

6 Ver BISSERET, Noëlle. Les inégaux ou la sélection universitaire. Paris: PUF, 1974.

7 A autora emprega o termo mixité (N. de T.)

8 Ver o relatório de pesquisa de Clotilde Lemarchand. Être minoritaire au lycée et en CFA: garçons et en filles atypiques dans les formations techniques courtes en Haute-Normandie (2009).

9 A relação com o saber é definida por essa equipe como um processo pelo qual um sujeito, a partir de saberes adquiridos, produz novos saberes singulares, que lhe permitem pensar, transformar e sentir o mundo natural e social. Essa definição sublinha as dimensões ativas e criativas do sujeito em relação ao seu saber. Trata-se de um processo criador que faz de todo sujeito um autor de saber (Beillerot, 1997)

10 Em um total de 309 interações, 205 são realizadas com meninos (59,1\%) e 104 com meninas $(40,9 \%)$

Educação \& Realidade, Porto Alegre, v. 39, n. 1, p. 221-239, jan./mar. 2014.

Disponível em: <http://www.ufrgs.br/edu_realidade> 
Escola Mista e Igualdade entre os Sexos no Contexto Francês

$1160,7 \%$ para os meninos e 39,3\% para as meninas. Por vezes, há interações com vários alunos de uma única vez, o que explica por que o tempo pode exceder o recorte temporal da aula propriamente dita.

12 Constata-se que dois alunos $(8 \%$ do número total de alunos presentes na aula desse dia) monopolizam, sozinhos, um quarto das interações; ou que os seis alunos mais silenciosos (23\% dos participantes) totalizam apenas $5 \%$ das interações (em uma relação de 1 a 15).

$1359,7 \%$ com as meninas e 40,3\% com os meninos, depois de certas ponderações feitas.

\section{Referências}

ACHERAR, Leila. Filles et Garçons à l'École Maternelle. Rapport Commandé par le DRDFE et le Centre d'Information sur le Droit des Femmes. 2003. Disponível em: <http://www. inegalites.fr/IMG/pdf/etude_maternelle.pdf>. Acesso em: 12 set. 2011.

BAUDELOT, Christian; ESTABLET, Roger. L'Ecole Capitaliste en France. Paris: François Maspero, 1971

BAUDELOT, Christian; ESTABLET, Roger. Allez les Filles! Paris: Seuil, 1992.

BEILLEROT, Jacky. Dictionnaire de l'Éducation et de la Formation. Paris: PUF, 1997.

BLANCHARD-LAVILLE, Claudine (Org.). Variations sur une Leçon de Mathématiques: analyse d'une séquence: l'écriture des grands nombres. Paris: L'Harmattan, 1997.

BLANCHARD-LAVILLE, Claudine. Approches Cliniques d'Inspiration Psychanalytique. Revue Française de Pédagogie, Paris, n. 127, p. 9-22, 1999.

BLANCHARD-LAVILLE, Claudine. De la Co-Disciplinarité en Sciences de l'Éducation, Revue Française de Pédagogie, Paris, n. 132, p. 55-66, 2000.

BOLTANSKI, Luc. Prime Éducation et Morale de Classe. Paris: Mouton et Cie., 1968.

BOURDIEU, Pierre; PASSERON, Jean-Claude. A Reprodução: elementos para uma Teoria do Sistema de Ensino. Rio de Janeiro: Francisco Alves, 1975.

BYRNE, Evelyne M. Women and Education. London: Tavistock publications, 1978.

CACOUAULT-BITAUD, Marlaine. Professeur... Mais Femme: carrières et vies privées dans enseignantes du secondaire au XXè siècle. Paris: La Découverte, 2007.

DALE, Reginald Rowland. Mixed or Single-Sex School? v. 1: a research study in pupil-teacher relationships. London: Routledge \& Keagan Paul, 1969.

DALE, Reginald Rowland. Mixed or Single-Sex School? v. 2: some social aspects. London: Routledge \& KeganPaul, 1971.

DALE, Reginald Rowland. Mixed or Single-Sex School? v. 3: attainment, attitudes and overview. London: Routledge \& KeganPaul, 1974.

DEEM, Rosemary. Women and Schooling. London: Routledge \& Keagan Paul, 1978.

DORLIN, Elsa. Genre, Sexe et Sexualités. Paris: PUF, 2008.

DURU-BELLAT, Marie. L'École des Filles: Quelle formation, pour quels rôles sociaux? Paris: L’Harmattan. 1990.

DURU-BELLAT, Marie. Filles et Garçons à l'École, Approches Psychologiques et Psycho-sociales. 2. La Construction Scolaire des Différences entre les Sexes. Revue Française de Pédagogie, Paris, n. 110, p. 75-110, 1995. 
FÉLOUZIS, Georges. Le Collège au Quotidian. Paris: PUF, 1994.

FORQUIN, Jean-Claude, L'approche Sociologique des Contenus et Programmes d'Enseignement. Perspectives Documentaires en Sciences de l'Éducation, Paris, n. 5, p. 31-70, 1985.

HURTIG, Marie-Claude; PICHEVIN, Marie France. La Différence des Sexes: question de psychologie. Paris: Tierce, 1986.

JARLÉGAN, Annette. La Fabrication des Différences: sexe et mathématiques à l'école élémentaire. 1999. Tese (Doutorado em Ciências da Educação) - Université de Bourgogne, Dijon (FR), 1999.

KANDEL, Liliane, L'École des Femmes et le Discours des Sciences de L'homme. In: BEAUVOIR, Simone de (Org.). Les Femmes s'Entêtent. Paris: Gallimard, 1975. P. 86-128.

LE DOEUFF, Michele. Le Sexe du Savoir. Paris: Aubier, 1998.

MARRO, Cendrine. La Dépendance/Indépendance à l'Égard du Genre. Paris: L'Harmattan, 2011

MARRY, Catherine. Masculin-Féminin: questions pour les sciences de l'homme. Paris: PUF, 2001

MARUANI, Margaret; NICOLE-DRANCOURT, Chantal. La Flexibilité à Temps Partiel: Conditions d'emploi dans le commerce. Paris: La Documentation Française, 1989.

MOREAU, Gilles. Filles et Garçons au Lycée Professionnel. Paris: L'atelier, 1994.

MOSCONI, Nicole. La mixité dans l'enseignement secondaire: un faux-semblant. Paris: PUF, 1989

MOSCONI, Nicole. Liliane Kandel: Génération MLF. Revue Travail, Genre et Societé, n. 24, p. 5-24, 2010.

MOSCONI, Nicole; BEILLEROT, Jacky; BLANCHARD-LAVILLE, Claudine. Formes et Formation du Rapport au Savoir. Paris: L'Harmattan, 2000.

PASSERON, Jean-Claude; DE SINGLY, François. Différences dans la Différence: socialisation de classe et socialisation sexuelle. Revue Française de Sciences Politiques, Paris, n. 34, p. 48-78, 1984.

PICHEVIN, Marie-France. De la Discrimination Sociale entre les Sexes aux Automatismes Psychologiques: serions-nous tous sexistes? Paris: Ephesia/Éditions La Découverte, 1995.

SAYAC-SLAWINKI, Réjane. L'Ordre Sexué: la perception dês inégalité femmeshommes. Paris: PUF, 2007.

SPENDER, Dale. Invisible Women: The Schooling Scandal. London: Cooperative Society, 1982.

YOUNG, Michael. Knowledge and Control. London: Collier-Mac Millan ed., 1971. ZAIDMAN, Claude. La Mixité à l'École Primaire. Paris: L’Harmattan, 1996.

Nicole Mosconi é professora agrégée de Filosofia e doutora em Ciências da Educação. Professora emérita em Ciências da Educação da Universidade Paris Ouest Nanterre La Défense. Integrante do Grupo de Pesquisa: Genre, savoirs et éducation.

E-mail: nicole.mosconi@outlook.fr

Tradução de Mônica Terezinha de Souza e Mônica Maria Farid Rahme 